\title{
Paternalist Liderlik ve Psikolojik Güçlendirme Arasındaki İlişkide Temel Benlik Değerlendirmesinin Düzenleyici Etkisi: Dış Ticaret Firmalarında Bir Araştırma ${ }^{1}$
}

\author{
The Moderating Effect of Core Self-Evaluation on The Relationship Between \\ Paternalistic Leadership and Psychological Empowerment: A Research in Foreign \\ Trade Companies
}

\author{
Aslihan TURGUT *

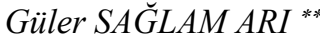

$\ddot{O} Z$

Uluslararası iş çevresinde faaliyet gösteren işletmelerin değişimlere hızl tepki vermesi ve rekabet üstünlüğü sağlamasında personel güçlendirme önemli bir değişkendir. Çalışanların kendilerini güçlendirilmiş hissetmesinde etkili olan öncül değişkenleri ortaya koymak işletmelerin uygulamalarını yönlendirecektir. Bu çalışmada, paternalist liderlik ile psikolojik güçlendirme arasındaki ilişki ve bu ilişkide temel benlik değerlendirmesinin düzenleyici etkisi araştırılmıştır. Araştırma verileri Kayseri' de üç farklı sanayi bölgesinde faaliyet gösteren dış ticaret firmalarından tabakalı örneklemle seçilen 274 katılımcıdan elde edilmiştir. Verilerin analizinde aritmetik ortalama, standart sapma, korelasyon, doğrusal ve hiyerarşik regresyon analizi kullanılmıştır. Araştırma sonucunda paternalist liderlik ile psikolojik güçlendirme arasında anlamll ve pozitif ilişki bulunmuş, bu ilişkide temel benlik değerlendirmesinin düzenleyici rolü olduğu tespit edilmiştir.

\section{ANAHTAR KELIMELER}

Paternalist Liderlik, Psikolojik Güçlendirme, Temel Benlik Değerlendirmesi, Dış Ticaret Firmaları

\begin{abstract}
Employee empowerment is an important variable for businesses operating in the international business environment to respond quickly to changes and provide competitive advantage. Revealing the antecedent variables that are effective in making employees feel empowered will guide the practices of businesses. In this study, the relationship between paternalistic leadership and psychological empowerment and the moderating effect of core self-evaluation on this relationship were investigated. The research data were obtained from 274 participants selected by stratified sampling from foreign trade companies operating in three different industrial zones operating in Kayseri. The data were analyzed using mean, standard deviation, correlation, linear and hierarchical regression analysis. As a result of the research, a significant and positive relationship was found between paternalistic leadership and psychological empowerment, and it was determined that core self-evaluation had a moderating role in this relationship.
\end{abstract}

\section{KEYWORDS}

Paternalistic Leadership, Psychological Empowerment, Core Self-Evaluation, Foreign Trade Companies.

\begin{tabular}{|c|c|c|}
\hline \multicolumn{2}{|r|}{$\begin{array}{l}\text { Makale Geliş Tarihi / Submission Date } \\
\text { 29.07.2021 }\end{array}$} & $\begin{array}{c}\text { Makale Kabul Tarihi / Date of Acceptance } \\
\text { 02.09.2021 }\end{array}$ \\
\hline Atıf & $\begin{array}{l}\text { Turgut, A. ve Sağlam Arı, G. (2021). P. } \\
\text { Değerlendirmesinin Düzenleyici Etkisi } \\
\text { Meslek Yüksekokulu Dergisi, } 24 \text { (2), } 44\end{array}$ & $\begin{array}{l}\text { ikolojik Güçlendirme Arasındaki İlişskide Temel Benlik } \\
\text { nda Bir Araştırma. Selçuk Üniversitesi Sosyal Bilimler }\end{array}$ \\
\hline
\end{tabular}

\footnotetext{
${ }^{1}$ Bu çalışma, Prof. Dr. Güler SAĞLAM ARI danışmanlı̆̆ında Arş. Gör Aslıhan YALDIZ TURGUT' un tamamlamış olduğu "Paternalist Liderlik ile Psikolojik Güçlendirme Arasındaki İlişkide Temel Benlik Değerlendirmesinin Düzenleyici Etkisi: Kayseri İli Sektörel Dış Ticaret Şirketleri Üzerine Bir Araştırma" başlıklı yüksek lisans tezinden üretilmiştir.

Bu çalışmanın bir kısmı 6-8 Nisan 2017 tarihleri arasında Alanya -Türkiye'de gerçekleştirilen "International Congress of Eurasian Social Sciences (ICOESS")" 'da sözlü bildiri olarak sunulmuştur.

*Arş. Gör., Alanya Alaaddin Keykubat Üniversitesi İktisadi ve İdari Bilimler Fakültesi, aslihan.yaldiz@alanya.edu.tr, ORCID: 0000-0002-7836-8513

** Prof. Dr., Ankara Hacı Bayram Veli Üniversitesi İktisadi ve İdari Bilimler Fakültesi, guler.saglam@ hbv.edu.tr, ORCID: 0000-0002-4411-6609
} 


\section{GíRiş}

Küresel rekabet ortamında, çalışanların inisiyatif kullanabilmesi ve yenilikçiliği önem kazanmakta bu da personel güçlendirmenin işletmeler açısından önemini artırmaktadır. Personel güçlendirme; örgütsel performans ve büyüme için umut verici bir değişken olarak görülmekte, lider ile ilişkilerin, güçlendirmeyi destekleyici yönde olması beklenmektedir (Pradhan vd., 2017). Personel güçlendirmenin yapısal ve psikolojik olmak üzere iki boyutu vardır. Bu boyutlardan ilki karar almanın üst kademelerden alt kademelere doğru aktarılması ve alt kademelerin enformasyon ve kaynaklara ulaşabilmesinde gerekli örgütsel uygulamalarda kendini göstermektedir. Diğer boyut ise çalışanların algısına dayalıdır. İşletmeler çalışanları güçlendirmek için bazı uygulamalar yapabilir ama bu personelin kendisini güçlendirilmiş hissettiği anlamına gelmemektedir. Bu çalışmanın da konusunu oluşturan psikolojik güçlendirme; çalışanın işe yöneliminde işine dair anlam, yeterlilik, seçim ve etkiye sahip olması ile şekillenen dört bilişsel durumu yansıtan içsel görev motivasyonu olarak tanımlanmaktadır (Thomas ve Velthouse, 1990; Spreitzer, 1995; Maynard vd., 2012; Sağlam Arı, 2014). Psikolojik güçlendirme düzeyi yüksek olan birey, yaptığ iş̧in değerli olduğunu bildiği için içsel olarak kendisini motive olmuş hissetmekte, işinde yeterli olduğunu düşünmekte, işi üzerinde kontrole ve kendi başına gerçekleştirdiği faaliyetleri düzenleme seçeneğine sahip olduğunu bilmektedir. Böylece çalışanlar farklı görevleri yerine getirirken daha yaratıcı ve yenilikçi olabilmektedir (Mubarak ve Noor, 2018). Durum sadece işletmeler için olumlu etkiler yaratmamakta, bireyler açısından da doyumlu olmayı, mutluluğu ve iyi hissetmeyi beraberinde getirmektedir (Taştan Bal, 2013; Li ve Lin, 2020; Ahmed ve Malik, 2019). Psikolojik güçlendirmenin çalışanlar ve işletmeler açısından önemi nedeniyle alan yazında araştırmalar, psikolojik güçlendirmeyi etkileyen durum ve değişkenlerin belirlenmesine yoğunlaşmıştır. Bu araştırmaların bir kısmı da, psikolojik güçlendirme ve liderlik ilişkisine odaklanmıştır ( Avolio vd., 2004; Wei vd., 2010; Pieterse vd., 2010; Li vd., 2012; Krishnan, 2012; Joo ve Lim, 2013; Pradhan vd., 2017; Newman vd., 2017; Hu vd., 2018; Mubarak ve Noor, 2018; Zhang vd., 2018; Grošelj, vd., 2021).

Yönetim ve liderlik yazınında liderliğin kültüre özgü olup olmadığı veya farklı kültürler için etkili liderlik tarzlarının nasıl şekillendiği uzun süredir araştırılmaktadır. Bu konuya açıklık getirmek için üzerinde durulan liderlik tarzlarında birisi de paternalist liderliktir (Goodell vd., 1985; Lee vd., 2014; Mansur vd., 2017). Paternalist liderlik baba şefkati ve ahlaki dürüstlük ile birleştirilmiş güçlü disiplin ve otoriteye dayalı bir liderlik etme şekli olarak tanımlanmaktadır (Farh ve Cheng, 2000). Kavram yönetici ile çalışanlar arasındaki ilişskinin niteliğini ortaya koymaktadır (Aycan, 2001). Lider, paternalizme özgü davranışlar sergileyerek takipçilerin saygısını, bağlılığını kazanabilmekte ve onların güvenlik, korunma ve aile benzeri bir ortamda çalışma ihtiyacını karşılamaktadır (Pellegrini ve Scandura, 2006). Lider ve çalışan arasında bu tür bir ilişkinin geliştirilmesi, paternalizmin yaygın kabul gördüğü kültürlerde bireyin kendisini güçlendirilmiş hissetmesinde belirleyici olabilecektir (Mubarak ve Noor, 2018). Yapılan çalışmalarda paternalist liderliğin Türk kültüründe etkili bir liderlik tarzı olduğu ortaya konulmaktadır (Pellegrini ve Scandura, 2006; Lau vd., 2019).

Alan yazında etkili liderliğin hangi faktörlerle açıklanabileceği farklı değişkenlerle incelenmektedir (Lin ve Sun, 2018). Son zamanlarda bazı çalışmalarda birkaç kişilik değişkeninin liderlik için önemli olduğu, kişinin kendi etkinliğinin ve değerliliğinin önemli bir değerlendirmesi olan temel benlik değerlendirmesinin liderliğin etkililiğinde özellikle belirgin olduğu keşfedilmiştir (Hu vd., 2012). Bu çalışmada da çalışanın liderlik tercihini açıklayabilme potansiyeli ile birlikte psikolojik güçlendirmede belirleyici olabilecek temel benlik değerlendirmesinin düzenleyici etkisi araştırılacaktır. Bireyin kendisi, yetenekleri ve kontrol gücü hakkındaki değerlendirmelerini içeren temel benlik değerlendirmesi, liderin sergilediği paternalist davranışların psikolojik güçlendirmeyi etkilemesinde düzenleyici bir etki yaratabilecektir (Judge vd., 2003). Alan yazında paternalist liderlik, psikolojik güçlendirme ve temel benlik değerlendirmesi kavramları arasında ilişkiler tespit eden, paternalist liderliğin psikolojik güçlendirmeyi etkilediğini ortaya koyan bazı çalışmalar yer almaktadır (Demirer, 2012; Dust vd., 2018; Lin vd., 2015; Dedahanov vd., 2019). Ancak, temel benlik değerlendirmesinin paternalist liderlik ile psikolojik güçlendirme arasındaki ilişkide düzenleyici rolü belirlenmemiştir.

Uluslararası alanda iş yapan işletmeler için çevresel karmaşıklığın yüksek olması nedeniyle, personelin inisiyatif alarak hızlı karar alması rekabet avantajı yaratmaktadır. Psikolojik güçlendirme olumlu sonuçları ile bu işletmeler için hayati önemdedir. Bu araştırmada Kayseri'de uluslararası ticaretle uğraşan dış ticaret firmalarında paternalist liderliğin psikolojik güçlendirmeyi nasıl etkilediği temel benlik değerlendirmesinin düzenleyici etkisi ile birlikte incelenecektir. Paternalizmin etkili olduğu sektörlerin sırası ile; kolluk kuvvetleri, turizm ve üretim sektörleri şeklinde sıralandığı belirlenmiştir (Bedi, 2020). Araştırmalar belli sektörlerle sınırlı kalmış, farklı kültürlerle iş yapan, karmaşık bir çevrede faaliyet gösteren dış ticaret firmalarında bu değişkenlere dair bulgular belirlenmemiştir. 
Çalışmada öncelikle paternalist liderlik, psikolojik güçlendirme ve temel benlik değerlendirmesi alan yazın 1şığında incelenerek araştırma hipotezleri sunulacaktır. Daha sonra araştırma yöntemine dair bilgiler verilerek araştırma sürecinde elde edilen bulgular tartışılacak, araştırma kısıtları ve gelecekteki çalışmalar için öneriler geliştirilecektir. Araştırma sonuçlarının uluslararası iş yapan işletmeler için katkı sağlayacağı düşünülmektedir. Paternalizmin yaygın olduğu bir ülke olarak Türk kültürüne dair ortaya koyulan bulgular benzer ülke kültürlerindeki uygulamalar açısından da açıklayıcı olacaktır.

\section{KAVRAMSAL ÇERÇEVE}

\subsection{Paternalist Liderlik}

Paternalist liderlik, Çin kökenli Konfüçyanizmin etkisi ile genellikle Asya kültürlerine yayılmış bir liderlik tarzı olarak bilinir (Zhang vd., 2015). Silin (1976: 22,36) Tayvan'da faaliyet gösteren işletmelerin sahipleri ve yöneticileri ile gerçekleştirdiği araştırmasında, Batılı işletmelerden farklı olarak yöneticilerin merkezi bir otoriteye sahip olduklarını, isteklerini üstü kapalı bir şekilde dile getirdiklerini, kontrol taktikleri uyguladıklarını ve çalışanlar ile sosyal mesafeyi koruduklarını gözlemlemiştir. Paternalist liderlik baba şefkati, katı disiplin ve ahlaki liderlik davranışının bütünleştiği bir liderlik tarzıdır (Cheng, Chou ve Farh, 2000). Paternalist lider takipçi ilişkisinde bir yandan etki için kontrol etme, bir yandan onların iyiliği için endişelenme ile ortaya çıkan ikilem doğu felsefesindeki Ying-Yang'a benzetilmektedir. Otoriterlik, yardımseverlik ve ahlaki liderlik görünüşte zıt gibi görünmekle birlikte bir arada olabildikleri ve tamamlayıcı oldukları öne sürülmektedir (Bedi, 2020). Paternalist liderlik birey için, yöneticinin, ebeveynin temsil ettiği otorite figürünün mutasyona uğramış şekli olarak karşılık bulan bir liderlik tarzını yansıtmaktadır (Pellegrini ve Scandura, 2008).

Paternalizm alan yazınında konuya ilişkin olarak iki farklı görüş üzerinde durulmaktadır. İlki, paternalist liderliği otorite, yardımseverlik ve ahlak olmak üzere üç ayrı boyutta ele alan boyutsal yaklaşımdır (Farh ve Cheng, 2000; Hiller vd., 2019). Bu yaklaşım çıkarcı yaklaşım olarak da isimlendirilmekte ve yapılan işe vurgu yapılmaktadır (Aycan, 2001). Otoriterlik boyutu liderin astlar üstünde mutlak otoriteye sahip olduğu ve kararları tek başına aldığı bir liderlik türüdür. Otoriter liderliği karakterize eden somut davranışlar kontrol ve tahakküm, yüce bir imaj oluşturmak, astları didaktik bir tarzda eğitmek şeklinde sıralanabilir. Yardımseverlik boyutunda lider, hem işle ilgili konularda hem de kişisel konularda çalışanlarına yardımcı olmaktadır. Ahlaki liderlik, liderin çalışana örnek olacak şekilde adil, saygılı ve dürüst davranması olarak tanımlanmıştır (Dedahanov vd., 2019; Lau vd., 2019). Paternalizmi açıklayan ikinci görüş, iyilikseverlik ağırlıklı bir vurgu yaparak çalışanın iyiliğini ön plana almaktadır. Paternalist liderliğe bu tür bir yaklaşım; işyerinde bir aile ortamı yaratmak, astlarla yakın ve kişiselleştirilmiş ilişkiler kurmak, çalışanların iş dışı yaşamlarına dâhil olmak, astlardan sadakat ve hürmet beklemek, yetki ve statü hiyerarşisini sürdürmek şeklinde beş özellikle kavramsallaştırılmıştır. Bu yaklaşımda çalışan bağlılığ liderin iyi niyetine, samimiyetine ve cömertliğine karş11ık gelişen bir durumdur (Aycan, 2001; 2006a; Aycan vd., 2013; Hiller vd., 2019). Son dönemdeki bazı görüssler ise, hem yardımseverlik hem de kontrolün bir arada olması halinde paternalizmden söz edilebileceği, yardımseverlik olmadan kontrolün saldırgan ve düşmanca algılanacağı, yardımseverlik gösteren bir liderin de kontrol sergilemeden paternalist algılanmayacağı yönündedir (Wagstaff vd., 2015; Bedi, 2020).

Paternalist liderlik doğu kültürlerinde korumacı ve iyiliksever olarak algılanırken batı kültürlerinde otoriter olarak görülmekte, hatta "iyi niyetli gibi görünen bir diktatörlük" benzetmesi dahi yapılmaktadır (Aycan vd., 2000; Aycan, 2001; Pellegrini ve Scandura, 2008). Batı yazınında paternalizm, kurumsal sistemlerde, bireysel hak ve özgürlüklerin yasalarla korunduğu toplumlarda istenmeyen ve işlevsiz bir durum olarak nitelendirilmektedir. Ancak doğu kültürlerinde aile ilişkileri örgütlere taşınmaktadır (Paker, 2000'den aktaran Aycan, 2001). Yüksek bireysellik düzeyine sahip batı toplumlarının paternalistik yaklaşımı kabullenmesi zor iken, kolektivist ve yüksek güç mesafesine sahip ülkeler paternalizmi daha kolay kabul etmektedir. Türkiye de paternalizmi daha kolay kabul edebilecek ülkelerden biridir (Pellegrini ve Scandura, 2006). Paternalizmin güç dağılımında eşitsizliğin olduğu hiyerarşik toplumlarda daha çok kabul görmesinin sebebi liderin astları için en iyi olan ne ise bildiği düşüncesidir. Aycan vd., (2000) 10 farklı ülkede gerçekleştirdiği çalışmada, Pakistan, Çin ve Türkiye'de yüksek paternalist özelliklerin görüldüğü saptanmıştır. Araştırmalar, otoriter paternalizm örneği için Güney Kore'yi gösterirken Türkiye'de iyiliksever bir paternalizme dair bulgular ortaya koymaktadır (Paşa vd., 2001). Paternalizmin yüksek olduğu Türkiye'de, çalışanların proaktif olmadıkları, işlerini bağımsız bir şekilde ve inisiyatif alarak yapamadıkları inancının da yaygın olduğu gözlenmektedir (Aycan, 2001). 


\subsection{Psikolojik Güçlendirme}

Küresel iş ortamında ve karmaşık bir çevrede işletmelerin, gerek müşterileri ile ilişkilerinde gerekse içsel operasyonlarında hızlı karar verebilmesi, çalışanların karar verebilme yetkinliğine bağlıdır. Bu yetkinlik ihtiyacı, personel güçlendirme konusundaki çalışmaları teşvik etmiştir. Personel güçlendirme, bireylerde güçsüzlük hissi yaratan durumların belirlenerek, biçimsel ve biçimsel olmayan unsurlarla onların öz-yeterlilik duygusunun artırılması süreci olarak tanımlanabilmektedir (Conger ve Kanungo, 1988). Personel güçlendirmede bilgi ve kaynakların alt kademelerle paylaşılması yönetsel uygulamaları yansıtırken psikolojik güçlendirme yönetsel uygulamalar ve durumsal özelliklerden farklı olarak bireylerin bu durumlara dair bilişini ve psikolojik deneyimini ifade etmektedir (Spreitzer, 1995). Psikolojik güçlendirme; anlam, yeterlik, seçim, ve etki olmak üzere dört boyutla ifade edilen içsel görev motivasyonu şeklinde tanımlanabilir. Anlam bir işin veya görevin algılanan değerini ve birey için anlam ifade etmesini, yeterlik bireyin örgütsel faaliyetleri gerçekleştirmek için gerekli becerilere sahip olduğuna inanma derecesini, seçim kendi kendine gerçekleştirilen eylemleri başlatma ve düzenlemeyi, bağımsız hareket edebileceğini hissetmesini, etki ise kişinin işinde kontrolü olduğunu dolayısı ile etkili olduğuna dair yaptığı çıkarımları ifade etmektedir (Thomas ve Velthouse, 1990; Zimmerman, 1995; Spreitzer, 1995, 1996; Ergeneli vd., 2007; Krishnan, 2012; Sağlam Arı, 2014; Pradhan, vd., 2017). Psikolojik güçlendirme düzeyi yüksek olan çalışanların işlerini başarılı bir şekilde gerçekleştirme konusunda kendilerini daha yetkin hissettikleri, kuruluşlarına daha yüksek seviyede bağlı oldukları, örgütten ayrılma niyetlerinin daha düşük ve iş performanslarının da daha yüksek olduğu bilinmektedir (Meyerson ve Kline, 2008).

\subsection{Paternalist Liderliğin Psikolojik Güçlendirmeye Etkisi}

Alan yazında, işletmelerde paternalist liderliğin sonuç ve etkilerine dair araştırmalar yer almaktadır. Çalışmalardan bir kısmında tek boyutlu ölçümler bir kısmında da çok boyutlu ölçümler kullanılmaktadır (Bedi, 2020). Araştırmalara göre, yardımsever ve ahlaki davranışlar çalışanları olumlu etkilerken otoriter davranışlar olumsuz etki yaratmaktadır (Mussolino ve Calabrò, 2014). Yardımsever paternalizmin duygusal ve devam bağlılı̆̆ını artırdığı belirlenmiştir (Erben ve Güneşer, 2008). Meta analiz çalışmalarından elde edilen bulgular; ahlaki liderlik ve yardımseverliğin güven, iş tatmini, örgütsel vatandaşlık davranışı, iş performansı ve lider üye etkileşiminde artış, işten ayrılma niyetinde azalma olmak üzere olumlu sonuçlara, buna karşın otoriter boyutun ise tersi yönde olumsuz sonuçlara yol açtığını ortaya koymaktadır (Pellegrini ve Scandura, 2008; ZhiHua, 2016; Bedi, 2020). Yine bazı ampirik araştırmalar, paternalist liderliğin örgütsel performans, örgütsel adalet, örgütsel öğrenme, takım performansı, takım etkileşimi, örgütsel bağl1lık, duygusal sunum, iş tatmini, çalışanların psikolojisi ve güçlendirilmesi üzerindeki etkilerini belirlemektedir (Lin vd., 2015; Demirer, 2012).

Paternalizmin ahlaki ve yardımseverlik boyutunda liderler, çalışanların bağımsızlığına önem verdiklerinden ve çalışanlarını işleri ile ilgili konularda desteklediklerinden, bireyler kendilerini güçlendirilmiş hissedebilecektir. Ahlaki liderler çalışanlara saygılı davranır, görevlerinde kendi seçimlerini yapma konusunda onlara imkân tanır, bu durum güçlendirmeyi artırabilir. Çalışanlara sağladıkları yapıcı geri bildirimler de yeterlik ve etki hissetmelerini sağlayabilir. Ahlaki değerlerin sağlayacağı olumlu çalışma iklimi bireylerin psikolojik güçlendirmesini artırabilecektir. Yardımsever liderler, bireylerin beceri gelişimini destekleyeceği için bu gelişim bireyin işe uygunluğunu destekleyecek, anlam, yeterlik, seçim ve etki düzeyinde artış gerçekleşebilecektir. Buna karşın, otoriter liderler katı kurallarla yönetilen yapılar yarattıkları ve çalışanlarından itaat beklediklerinden bireyler daha az etkiye sahip olmakta, kendilerini daha az güçlendirilmiş hissedebilmektedir (Amabile, 1988; Wang ve Cheng, 2010; Li vd., 2012; Demirer,2012; Dedahanov vd., 2019). Sınırlı otonomi ve otorite kişide güçsüzlük hissini artırmaktadır (Henry, 2005: 767). Dedahanov vd., (2019) çalışmalarında paternalist liderliğin ahlaki boyutu ile psikolojik güçlendirme arasında olumlu, otoriterlik boyutu ile olumsuz bir ilişki bulmuş, yardımseverlik boyutu ile psikolojik güçlendirme arasında ise ilişki tespit edememişlerdir. Demirer (2012) Türkiye'de 313 tam zamanlı çalışan üzerinde yaptığ1 araştırmasında, paternalist liderliğin psikolojik güçlendirmeyi artırdığını, liderin güvenilir algılanmasının bu ilişkiye aracılık ettiğini ortaya koymuştur. Bu çalışmanın sonuçlarına göre, iş zenginleştirmenin düşük olduğu durumlarda bile, paternalist liderlik yüksek ise çalı̧̧anların psikolojik güçlenme düzeyi artmıştır.

Sosyal mübadele teorisinde bireylerin sosyal ilişkilerde ve etkileşimlerdeki karşıllklılık normları esastır. Taraflardan birisi diğerinin yararına bir eylemde bulunduğunda karşı taraf da aynı şekilde davranmak durumunda hisseder. Bu statü olarak yukarıda olan birisi söz konusu olduğunda daha mümkündür (Gouldner, 1960; Bedi, 2020). Paternalist lider takipçi ilişkisi bu açıdan ele alındığında liderin yardımsever ve ahlaki davranışlarına karşılık takipçiler de bu yaklaşımlar karşısında işlerinde gördükleri destek ve örnek davranışlar için anlam, yeterlik, seçim ve etki hissedebilecektir. Paternalizmin otoriterlik boyutu itaati ve kontrolü 
vurgulasa da, bizim çalışmamızda Wagstaff ve arkadaşlarının (2015) yaklaşımı ile paternalizm bütünsel bir kavram olarak düşünülmüştür. Türkiye gibi kolektivist ve güç mesafesi yüksek bir kültürde, çalışanların lider tercihinin paternalizm olacağı ve bu ortamda kendilerini güçlendirilmiş hissedecekleri varsayımından hareket edilecektir. Paternalist lider takipçi ilişkisi, ebeveyn çocuk ilişkisine benzemektedir. Buna göre nasıl ebeveyn sevgisi ile kontrol/disiplin bir arada olabiliyor ise, bu ilişki de benzer bir yapıda şekillenmektedir. Bu birliktelik batıdaki ayrımda görev/ insan odaklı olmanın bir karışımı gibidir (Aycan, 2001). Ebeveynin çocuğunu hassas bir şekilde izlemesi, iyiliği ile ilgilenmesi ve son kontrolü elinde bulundurması gibi paternalist liderin yaptığı benzer bir tavırdır. Bu durum, çalışan açısından güçlendirmeyi destekleyecek güvenli bir alan yaratabilir. Kültürel olarak batıda otoriterlik olarak değerlendirilen bu liderlik tarzı, kolektivist ve güç mesafesi yüksek kültürlerde bireylerin alışık olduğu, kendini rahat, güvende ve etkili hissettiği korunaklı bir ortam yaratabilecek, psikolojik güçlendirmeyi de artırabilecektir (Demirer, 2012: 5). Bu bakışla liderlerin destekleyici davranışları çalışanların psikolojik güçlendirme düzeyini yükseltebilir. Kurulan teorik bağlantılar ve alan yazındaki çalışmalar göz önünde bulundurularak H1 hipotezi önerilmiştir,

H1: Paternalist liderlik ile psikolojik güçlendirme arasında bir ilişki vardır.

\subsection{Paternalist Liderlik ile Psikolojik Güçlendirme Arasındaki İlişkide Temel Benlik Değerlendirmesinin Düzenleyici Etkisi}

Temel benlik değerlendirmesi bireyin kendisi, yetenekleri ve kontrolü hakkındaki değerlendirmesini açıklayan geniş bir kişilik kavramı olarak tanımlanmaktadır (Judge vd., 2003). Temel benlik değerlendirmesi benlik saygısı, genelleştirilmiş öz-yeterlik, kontrol odağı ve duygusal istikrar olmak üzere dört alt faktörden oluşmaktadır (Judge vd., 1998). Benlik saygısı kişinin bir kişi olarak kendine verdiği genel değeri, genelleştirilmiş öz-yeterlik kişinin gerçekleştirme, başa çıkma ve başarılı olma yeteneğini, kontrol odağı kişinin hayatındaki geniş bir dizi faktörü kontrol edebilme inancını ve duygusal istikrar kendinden emin, güvenli ve istikrarlı olma derecesini ifade etmektedir (Judge ve Bono, 2001). Yüksek temel benlik değerlendirmesine sahip çalışanlar kendilerini yetenekli, değerli ve kontrol sahibi olarak görmektedirler. Düşük temel benlik değerlendirmesine sahip çalışanlar ise görevlerini olumsuz olarak görmekte, kontrollerinin ötesinde olduğunu düşünmekte ve başarılı olacaklarına inanmamaktadırlar. Sonuç olarak, bir görev üzerinde çalışmaya başlama konusunda motive değildirler ve düşük performans gösterme olasılıkları yüksektir (Nübold vd., 2013).

Paternalist liderliğin kabul edilebilirliği ve etkililiği çalışanların kendine özgü örtük liderlik teorileri, kişisel geçmişleri ve temel benlik değerlendirmelerinden etkilenebilmektedir. (Hiller vd., 2019; Wu vd., 2014; Usman vd., 2020). Nübold vd., (2013) dönüşümcü liderliğin, takipçilerin temel benlik değerlendirmelerinin yüksek veya düşük olmasına bağlı olarak motivasyon ve performans üzerinde farklı etkilerinin olduğunu tespit etmiştir. Zhang vd., (2018) otantik liderliğin proaktif davranışa etkisinde temel benlik değerlendirmesinin aracılık etkisinin olduğunu bulmuştur.

Alan yazında paternalizmle etkileşime girebilecek bir durum olarak, özerk ve bağımsız bireylerin paternalizmi reddedeceği öne sürülmüştür. Sonraki çalışmalar da hiyerarşiyi kabulü ifade eden gelenekselliği moderator olarak incelemeye yönelmiştir. Geleneksellik, otoriterliğe verilen tepkiyi değiştirmiş, geleneksellik düzeyi yüksek bireylerde otoriterlik özdeşleşmeyi, uyumu ve minnettarlığı artırmış, düşük olan bireylerde bu etki tersi yönde olmuştur (Pellegrini ve Scandura, 2008). Paternalizm, boyun eğme ve bağımlılık beklentisi nedeniyle özerklik, kendi kendine yetebilme ve karar verebilme gibi bireyci değerlerle çelişmektedir. Paternalizm aynı zamanda özerklik ve seçim hakkını kısıtlayan bir tarz olarak görülmektedir (Aycan, 2001). $\mathrm{Bu}$ tespit, paternalist liderlik ile psikolojik güçlendirme ilişkisinde takipçilerin temel benlik değerlendirmesinin bu ilişkiyi değiştirici bir etki yaratabileceğini düşündürmektedir. Temel benlik düzeyi düşük olan bireyler, paternalist liderliği, psikolojik güçlendirme hissedecek şekilde algılayabilecektir. Bireyin temel benlik değerlendirmesi yüksek ise paternalizm etkili olmayacaktır. Bu bağlantılarla, temel benlik değerlendirmesinin yüksek ya da düşük olmasının paternalist liderlik ile psikolojik olarak güçlendirme arasındaki ilişkiyi farklılaştıracağı düşünülmektedir. Bu düşünüşle, temel benlik değerlendirmesinin paternalist liderlik ile psikolojik güçlendirme arasındaki ilişkiyi düzenlemesi beklenerek H2 hipotezi önerilmiştir:

H2: Paternalist liderlik ile psikolojik güçlendirme arasındaki ilişkide temel benlik değerlendirmesi düzenleyici bir etkiye sahiptir. Temel benlik değerlendirmesi yüksek ise bu ilişki azalır.

Çalışmada, paternalist liderlik, psikolojik güçlendirme ve temel benlik değerlendirmesi arasındaki varsayımsal ilişkileri incelemek için bir araştırma modeli geliştirilmiştir. Araştırma modeli Şekil 1 'de sunulmuştur. 


\section{Şekil 1. Araştırma modeli}

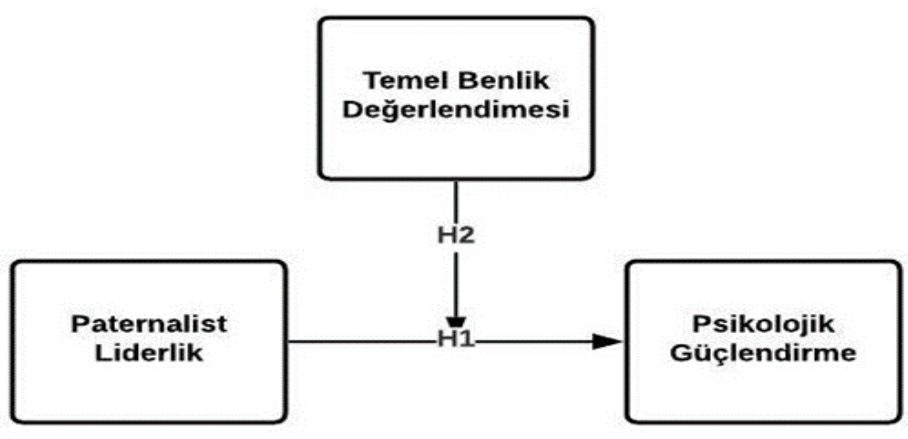

\section{YÖNTEM}

$\mathrm{Bu}$ çalışma, paternalist liderlik ve psikolojik güçlendirme ilişkisi ile bu ilişkide temel benlik değerlendirmesinin düzenleyici etkisini belirlemek amacıyla gerçekleştirilen ilişkisel nicel bir araştırmadır.

\subsection{Evren ve Örneklem}

Araştırmanın evrenini Kayseri' merkezde faaliyette bulunan 21 dış ticaret firmasının çalışanları oluşturmaktadır. Bu firmalar üç farklı sanayi bölgesinde toplandığı için örneklem belirlenirken tabakalı örnekleme yöntemi kullanılmıştır. Kayseri Organize Sanayi Bölgesi için 600, Mimar Sinan Organize Sanayi Bölgesi için 200 ve Kayseri Serbest Bölgesi için belirlenen 200 kişilik evren için 0,95 güven aralığında, 0,05 örneklem hatası ile evreni temsilen 278 kişi belirlenmiştir (Yazıcıŏlu ve Erdoğan,2004). Toplam 300 çalışana anket uygulanmış, 274 adet geçerli anket elde edilmiş ve bu anketler değerlendirmeye tabi tutulmuştur.

\subsection{Araştırmada Kullanılan Veri Toplama Araçları ve Verilerin Toplanması}

Paternalist liderlik ölçümünde Aycan (2006b) tarafindan geliştirilen ve Demirer'in (2012) çalışmasında kullandığı on madde ve tek boyuttan oluşan paternalist liderlik ölçeği (PLQ) kullanılmıştır. Psikolojik güçlendirmeyi ölçmek için Spreitzer (1995) tarafindan geliştirilen Türkçeye uyarması Sürgevil vd., (2013) tarafindan yapılan on iki madde ve dört boyuttan oluşan psikolojik güçlendirme ölçeği (PEI) kullanılmıştır. Temel benlik değerlendirmesi ölçümü içim Judge vd., (2003) tarafından geliştirilen Bayazıt (2003) tarafından Türkçe 'ye uyarlanan Kisbu'nun (2006) çalışmasında kullandığı on iki soru ve iki boyuttan oluşan temel benlik değerlendirmesi ölçeği (CSE) kullanılmıştır. Her bir ölçekteki maddeler "kesinlikle katılmıyorum" (1) ile "kesinlikle katılıyorum" (5) arasında değişen beşli Likert ile ölçülmüştür. Faktör analizi sonuçlarına göre psikolojik güçlendirme ölçeğinin 2,3 ve 4 . maddeleri birden fazla faktöre yüklendiği için analizden çıkarılmıştır. Her üç ölçek için de yapılan faktör analizleri sonucunda özdeğeri 1'den büyük olan birer boyut tespit edilmiştir.

Araştırma için etik kurul izinleri tamamlandıktan sonra firmalar ile iletişime geçilerek anketler elden verilmek sureti ile veriler toplanmıştır.

\section{VERILERIN ANALIZLERI}

Araştırma sonucunda elde edilen analizler SPSS 23 istatistik paket programı ile analiz edilmiştir. Analizler için ortalama, standart sapma, faktör analizi, korelasyon ve regresyon analizlerinden yararlanılmıştır.

\section{BULGULAR}

\subsection{Katılımcılara İlişkin Tanımlayıcı Bulgular}

274 katılımcının çoğunluğu erkektir (\% 86,5). Katılımcıların \%59.9’u 38 ve üzeri yaştadır. Eğitim kazanımı açısından katılımcıların \% 62,4'ü yüksekokul ve lise mezunudur. Çalışanların \% 69,7'si iş yerinde en az dört senedir görev yapmaktadır. Katılımcıların \% 66'sı bir üst yöneticisi ile bir yıldan daha uzun süredir birlikte çalışmaktadır.

\subsection{Değişkenler Arası İlişkilere Yönelik Bulgular}

Katılımcıların paternalist lidelik, psikolojik güçlendirme ve temel benlik değerlendirmesine ilişkin ortaya çıkan ortalama, standart sapma, güvenilirlik katsayıları ve korelasyon değerleri Tablo 1'de sunulmuştur. 
Tablo 1. Paternalist Liderlik, Psikolojik Güçlendirme ve Temel Benlik Değerlendirmesine İlişkin Ortalama, Standart Sapma, Korelasyon Değerleri ve Güvenirlik Katsayıları

\begin{tabular}{|l|l|l|l|l|l|}
\hline Değişken & Ortalama & SS & 1 & 2 & 3 \\
\hline 1.Paternalist Liderlik & 4,29 & 0,62 & $(0.722)$ & & \\
\hline 2.Psikolojik Güçlendirme & 4,35 & 0,51 & $0,409^{*}$ & $(0.794)$ & \\
\hline 3.Temel Benlik Değerlendirmesi & 4,10 & 0,71 & $-0,214^{*}$ & 0,072 & $(0.808)$ \\
\hline
\end{tabular}

Tablo 1'e göre paternalist liderlik ile psikolojik güçlendirme arasında pozitif yönlü, orta düzeyde istatistiksel bakımdan anlamlı bir ilişki vardır $(\mathrm{r}=0,409, \mathrm{p}<0,01)$. Bireyin paternalizm algısı arttıkça psikolojik güçlendirme düzeyi de artmaktadır. Temel benlik değerlendirmesi ile paternalist liderlik arasında düşük düzeyde negatif bir ilişki vardır $(r=-0,214, \mathrm{p}<0,01)$.

Ölçeklerin güvenirlik düzeyleri paternalist liderlik ölçeği 0.722, psikolojik güçlendirme ölçeği 0.794, temel benlik değerlendirmesi 0.808 olarak belirlenmiştir.

Paternalist liderlik ile psikolojik güçlendirme arasındaki tahminleyici ilişkiyi belirlemek üzere regresyon analizi yapılmıştır. Analiz sonuçları Tablo 2'de yer almaktadır.

Tablo 2. Paternalist Liderlik ve Psikolojik Güçlendirme Arasındaki İlişkiye Yönelik Regresyon Analizi Sonuçları

\begin{tabular}{|c|c|c|c|c|c|c|c|c|}
\hline $\begin{array}{c}\text { Bağımlı } \\
\text { Değişken }\end{array}$ & $\Delta R^{2}$ & Bağımsız Değişken & & Std.Ht. & $\mathbf{t}$ & p & $\mathbf{F}$ & $\mathbf{p}$ \\
\hline \multirow{2}{*}{$\begin{array}{c}\text { Psikolojik } \\
\text { Güçlendirme }\end{array}$} & \multirow{2}{*}{0,164} & Sabit Terim & 2,415 & 0,263 & 9,177 &, $000^{*}$ & \multirow{2}{*}{54,684} & \multirow{2}{*}{, $000^{*}$} \\
\hline & & Paternalist Liderlik & 0,451 & 0,061 & 7,395 &, $000^{*}$ & & \\
\hline
\end{tabular}

Tablo 2'de gösterildiği gibi model istatistiksel olarak anlamlıdır ( $\mathrm{F}=54,684 ; \mathrm{p}<.001)$. Model sonucu çalışanların paternalist liderlik algılamalarının psikolojik güçlendirmedeki değişikliğin \%16'sını açıklamaktadır. Bu sonuca göre paternalist liderlik ile psikolojik güçlendirme arasında bir ilişki olduğuna dair birinci hipotez kabul edilmiştir.

4.3. Paternalist Liderlik ile Psikolojik Güçlendirme Arasındaki İlişkide Temel Benlik Değerlendirmesinin Düzenleyici Etkisine İlişkin Hiyerarşik Regresyon Analizi Bulguları

Araştırmada teorik çıkarımlardan hareketle temel benlik değerlendirmesinin, paternalist liderlik ve psikolojik güçlendirme ilişkisinin şiddetini değiştirebileceği düşünülmüş, bu amaçla hiyerarşik regresyon analizi yapılmıştır. Analiz sonuçları Tablo 3'de gösterilmiştir.

Tablo 3. Paternalist Liderlik ile Psikolojik Güçlendirme Arasındaki İlişkide Temel Benlik Değerlendirmesinin Düzenleyici Rolüne İlişkin Hiyerarşik Regresyon Analizi Sonuçları

\begin{tabular}{|c|c|c|c|c|c|c|c|c|c|}
\hline & \multicolumn{3}{|c|}{ 1. Adim } & \multicolumn{3}{|c|}{ 2. Adim } & \multicolumn{3}{|c|}{ 3.Adım } \\
\hline & $B$ & s.h. & Beta & $B$ & s.h. & Beta & $B$ & s.h. & Beta \\
\hline \multicolumn{10}{|l|}{ Kontrol Değişkenleri } \\
\hline Yaş &, 050 & ,084 & ,024 &, 053 & ,088 & 030 &, 054 & ,089 & ,028 \\
\hline Cinsiyet &,- 025 &, 026 &,- 860 &,- 027 &, 022 &,- 071 &,- 027 &, 030 &,- 075 \\
\hline Eğitim & 073 & ,049 &, $173 *$ & ,072 & ,048 &, 150 & ,051 & ,048 &, 171 \\
\hline İş yerinde çalışma süresi &,- 051 &, 039 &,- 125 &,- 054 &, 031 &,- 097 &,- 055 &, 034 &,- 095 \\
\hline Bir üst yönetim ile çalışma süresi &, 037 & ,076 & 072 & ,039 & 087 &, 070 &, 040 & ,097 & ,088 \\
\hline \multicolumn{10}{|l|}{ Bağımsız Değişken } \\
\hline Paternalist Liderlik &, 478 & ,073 &, $509 *$ & ,398 &, 065 &, $427 *$ & ,431 & ,068 & ,440* \\
\hline \multicolumn{10}{|l|}{ Düzenleyici Değişken } \\
\hline Temel benlik değerlendirmesi & & & &, 436 & 053 &, $298 * *$ & ,368 & ,067 & ,019 \\
\hline Bağımsız * Düzenleyici Değişken & & & & & & & & & \\
\hline
\end{tabular}




\begin{tabular}{|c|c|c|c|c|c|}
\hline $\begin{array}{l}\text { Paternalist liderlik*Temel benlik } \\
\text { değerlendirmesi }\end{array}$ & & & ,269 & ,034 &, $487 * *$ \\
\hline$R^{2}$ & , 158 & , 173 & \multicolumn{3}{|c|}{,207 } \\
\hline$F$ & $6,164 *$ & $11,583^{*}$ & & 12,009 & \\
\hline
\end{tabular}

Tablo 3 'de gösterildiği gibi araştırma modeli üç aşamada istatistiksel olarak incelenmiş sonuçta modelin anlamlı olduğu bulunmuştur $(\mathrm{F}=6,164 \mathrm{~F}=11,583, \mathrm{~F}=12,009 ; \mathrm{p}<, 001)$.

İlk aşamada kontrol değişkenleri (yaş, cinsiyet, eğitim durumu, iş yerinde çalışma süresi ve bir üst yönetici ile çalışma süresinin) ve paternalist liderliğin psikolojik güçlendirme üzerine etkisine bakılmış eğitim durumu ve paternalist liderliğin psikolojik güçlendirme üzerinde istatiksel olarak anlamlı etkisinin olduğu ancak yaş, cinsiyet, iş yerinde çalışma süresi ve bir üst yönetici ile çalışma süresinin psikolojik güçlendirme üzerinde istatistiksel olarak anlamlı etkisinin olmadığı belirlenmiştir $(\beta=, 173 ; \beta=, 509 p<, 001)$. Model bu hali ile psikolojik güçlendirmenin \% 15,8'sini açıklamaktadır.

İkinci aşamada modele düzenleyici değişken olarak temel benlik değerlendirmesi eklenmiş modelin istatistiksel açıdan anlamlı olduğu tespit edilmiştir $(\beta=, 298 ; \mathrm{P}<, 01)$. Bu aşamada paternalist liderliğin psikolojik güçlendirmeyi etkileme gücü devam etmektedir ve model psikolojik güçlendirmenin \% 17,3 'ünü açıklamaktadır $(\beta=, 427 ; \mathrm{p}<, 001)$.

Modele son olarak üçüncü aşamada düzenleyici değişken ve bağımsız değişken birlikte eklenmiştir. $\mathrm{Bu}$ aşamada model istatistiksel açıdan anlamlıdır ve paternalist liderliğin psikolojik güçlendirmeyi etkileme gücü devam etmektedir $(\beta=, 487 ; \mathrm{p}<, 01)$. Modele göre değişkenler psikolojik güçlendirmenin $\% 20,7$ 'sini açıklanmaktadır.

Model sonucuna göre paternalist liderlik ile psikolojik güçlendirme arasındaki ilişkide temel benlik değerlendirmesi düzenleyici bir etkiye sahip olduğunu ileri süren ikinci hipotez desteklenmiştir.

Temel benlik değerlendirmesinin farklı düzeyleri için (yüksek ya da düşük) paternalist liderlik ile psikolojik güçlendirme arasındaki ilişkide nasıl bir değişim yarattı̆̆ını görmek amacıyla basit eğim testi yapılmıştır. Paternalist liderliğin düşük ve yüksek seviyelerinde sıfırdan farklı değerlere ulaşılmıştır. Paternalist liderlik ile psikolojik güçlendirme arasındaki pozitif ilişki temel benlik değerlendirmesi düşük olduğunda daha güçlüdür. Diğer bir deyişle yüksek temel benlik değerlendirmesine sahip çalışanlara gösterilen paternalist liderlik davranışlarının artması çalışanların psikolojik güçlendirmeleri üzerinde olumsuz etkiye neden olmaktadır. $\mathrm{Bu}$ bulgu şekil 2'de grafiksel olarak sunulmuştur.

\section{Şekil 2. Paternalist Liderlik ile Psikolojik Güçlendirme arasındaki İlişkide Temel Benlik Değerlendirmesinin Düzenleyici Etkisi}

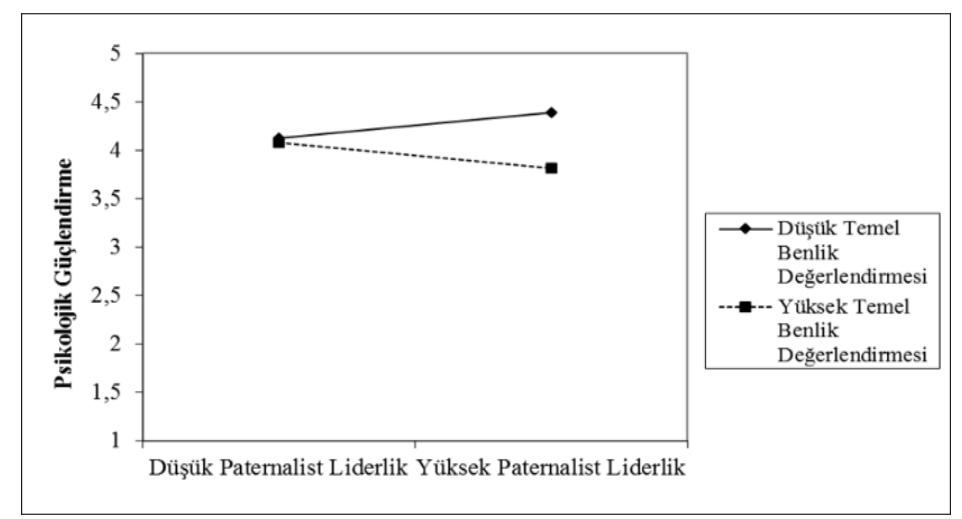

\section{SONUÇ VE TARTIŞMA}

Dış ticaret firmaları ekonomik, teknolojik, politik, yasal ve kültürel pek çok farklı çevresel değişkenin etkisi ile hızlı ve çevik hareket etmek durumunda olan işletmelerdir. Çalışanların psikolojik güçlendirme düzeyini etkileyen değişkenlerin açıklanması hem çalışan memnuniyeti hem de işletmelerin devamlılığı açısından işletme uygulamalarını şekillendirecektir. Bu çalışmada Kayseri'deki dış ticaret firmalarında psikolojik güçlendirme ile paternalist liderlik ilişkisi ve bu ilişkide temel benlik değerlendirmesinin düzenleyici etkisi araştırılmıştır.

Paternalist liderlik Türkiye ile benzer kültürel sınıflandırmalarda yer alan ülkeler için etkili bir liderlik tarzıdır. Paternalist liderliğin çalışanların tutum, davranış ve güçlendirmeleri üzerindeki etkileri ile ilgili 
çalışma sayısı hala sınırlıdır (Meyerson ve Kline, 2008; Hu vd., 2018; Khuwaja vd., 2020). Araştırma bulguları doğrultusunda paternalist liderliğin çalışanların psikolojik güçlendirme algısını artırdığı ortaya koyulmuştur. Çalışma sonuçları alan yazınla paralel sonuçlara ulaşmıştır (Bedi, 2020; Lin vd., 2015; Demirer, 2012; Dedahanov, 2019). Batı ve doğu kültürlerinde paternalist liderliğin anlamı farklılaşmaktadır. Kolektivizm ve güç mesafesinin yüksek olduğu kültürlerde paternalizm daha etkili bir liderlik tarzı olarak ortaya çıkmaktadır. Lider takipçi ilişkisi ebeveyn ilişkisi gibi algılandığı için, çalışanlar işyerlerinde de yöneticilerinden benzer bir ilişkiyi bekleyebilmektedir. Türkiye örnekleminde yapılan çalışmalarda bu tespit desteklenmiştir. Çalışanlar ebeveyn çocuk ilişkisinde olduğu gibi lider takipçi ilişkisinde de alışık oldukları ortamla güvenli bir alan arayabilmektedir. $\mathrm{Bu}$ araştırma ile paterernalist liderliğin psikolojik güçlendirmeye etkisi ve hangi çalışan özelliklerinde bu ilişkinin daha muhtemel olduğu belirlenerek alan yazına katkı sağlanmıştır. Çalışma sonuçlarının pratik etkileri değerlendirildiğinde, bireylerin psikolojik güçlendirme algılarının paternalist liderlikten etkilenmesi işletmelerdeki karar süreçlerini anlamak açısından önemli bir bulgudur. Türk kültüründe paternalist liderliğin etkilerinden birisi psikolojik güçlendirmeyi artırmasıdır. Önceki çalışmalar psikolojik olarak güçlendirilmiş çalışanların iş performansının ve iş tatminin yüksek işten ayrılma niyetlerinin düşük olduğunu göstermiştir (Hechanova vd., 2006; Tuuli ve Rowlinson, 2009; Ölçer ve Florescu, 2015; Marta vd., 2021). Paternalizm bu kültürde psikolojik güçlendirmeyi desteklemekte, psikolojik güçlendirmenin olumlu sonuçlarına katkı sağlamaktadır.

Çalışmanın bir diğer amacı doğrultusunda gerçekleștirilen analizlerle, temel benlik değerlendirmesinin, paternalist liderlik ile psikolojik güçlendirme arasındaki ilişkide düzenleyici etkisi bulunmuştur. Benlik saygisı, genelleştirilmiş öz yeterlik, kontrol odağ1 ve duygusal istikrardan oluşan temel benlik değerlendirmesinin yüksek olması paternalist liderliğin psikolojik güçlendirme üzerindeki etkisini azaltmaktadır. Takipçilerin kendisine verdiği değer, öz yeterliği, başına gelen olayları kendi kontrolünde algılama düzeyi ve duygusal dengesi arttıkça paternalist liderlik etkisini yitirmeye başlamaktadır. Bu tespit, örgütsel ilişkilerde batı ve doğu arasındaki farklılıkların temelinin, ebeveyn çocuk ilişkilerinden bağımsızlaşmak olduğunu düşündürmektedir. Paternalizm, boyun eğme ve bağımlılık beklentisi ile özerklik, kendi kendine yetme ve karar verme gibi bireyci değerlerle de uyuşmamaktadır (Aycan, 2001). Yine bu çalışmada, alan yazında, paternalizmle etkileşime girebilecek bir durum olarak özerk ve bağımsız bireylerin paternalizmi reddedeceği önermesi (Pellegrini ve Scandura, 2008) ile benzer bir sonuç gözlenmektedir. Alan yazında dönüşümcü liderlik ve otantik liderlikle bazı örgütsel sonuçlar arasındaki ilişkide temel benlik değerlendirmesinin düzenleyici etkileri belirlenmiştir (Nübold vd., 2013; Zhang vd., 2018). Ancak paternalist liderliğe dair ilk bulgu bu çalışma ile ortaya konulmuştur.

Paternalist liderlik ve psikolojik güçlendirme ilişkisinde temel benlik değerlendirmesinin düzenleyici etkisine dair bu sonuç, çalışanların paternalist liderlik davranışlarına farklı tepkiler vereceğini göstermektedir. $\mathrm{Bu}$ çalışmada gösterildiği gibi, yüksek düzeyde temel benlik değerlendirmesine sahip çalışanlar için paternalist liderlik etkili değildir. Bu sonuç hangi liderlik yaklaşımın daha etkili olacağı sorusunu akla getirmektedir. Hu vd. (2012) temel benlik değerlendirmesi ile dönüşümcü liderlik arasındaki ilişkiyi inceledikleri çalışmalarında, temel benlik değerlendirmesi ile dönüşümcü liderlik arasında pozitif bir ilişki olduğunu tespit etmişlerdir. Bu sonuçlar doğrultusunda, dönüşümcü lider özellikleri temel benlik değerlendirme düzeyi yüksek çalışanlar için etkili olma potansiyeline sahiptir. Türk kültürü ve farklı kültürler için bu sonuçlar gelecekte yapılacak araştırmalarla sınanabilir.

Ortak yöntem yanlılı̆̆ çalışmanın olası bir sınırlamasıdır. Bu sınırlama için gelecekteki çalışmalarda veriler farklı kaynaklardan toplanabilir. Çalışmada kullanılan kesitsel veriler ile yalnızca değişkenler arasındaki ilişki araştırılmıştır. Gelecekte değişkenler arasındaki etkileşimin olası eğilimlerini keşfetmek için boylamsal çalışmalar yapılabilir. Bu çalışmada sadece nicel yöntemler kullanılmıştır. Çalışanların algılarını yönetmek için derinlemesine görüşme ya da odak grup görüşmesi gibi alternatif nitel yöntemler nicel yöntemlerle birlikte kullanılabilir.

Araştırmada psikolojik güçlendirme ölçeği tek boyutlu olarak geçerlenmiş, alt boyutların etkisini belirlemek bu nedenle mümkün olmamıştır. Bu durum çalışma için bir kısıt olarak düşünülebilir.

Bugüne değin paternalist liderliğin etkili olduğu sektörler incelenmiştir. Bu araştırma uluslararası iş yapan işletmeler için bir bulgu sunmaktadır. Bu çalışmanın genellenebilirliği dış ticaret işletmeleri çalışanları ile sınırlıdır. Sonuçları genelleştirmek için gelecekteki araştırmalarda, farklı illerde faaliyet gösteren işletme çalışanları dâhil edilerek örneklem büyüklüğü genişletebilir. Ayrıca diğer liderlik yaklaşımları da dâhil edilerek değişkenler arasındaki ilişkiler ortaya konulabilir.

Türk işletmeleri ile batılı işletmelerin yapısı ve işleyişi arasında önemli farklılıklar olabilmektedir. Batı toplumunda bireyciliğe daha fazla öncelik verilirken, Türkiye'de kişiler arası uyum ve kolektif değerler daha ön plandadır. Bu yüzden paternalist liderlik ve psikolojik güçlendirme arasındaki ilişki çok uluslu firmalar 
açısından incelenerek kültür farklılaşmasının etkilerinin olup olmadığı tartışılabilir. Temel benlik değerlendirmesinin farklı kültürleri yakınlaştıran ve benzeştiren bir etkisi olabilir mi sorusu da bir araştırma sorusu olarak akla gelmektedir. Kolektivizm ve güç mesafesinin etkileri temel benlik değerlendirmesi yüksek bireyler açısından farklı olabilecek midir sorusu ile, kültüre dair araştırma modellerinde de temel benlik değerlendirmesinin düzenleyiciliğine yer verilebilir. 


\section{KAYNAKÇA}

Ahmed, Nisar ve Malik, Beenish, (2019) "Impact of Psychological Empowerment on Job Performance of Teachers: Mediating Role of Psychological Well-being", Review of Economics and Develpments Studies (READS), 5 (3), s. 451-460.

Amabile, Teresa M., (1988) "A model of creativity and innovation in organizations", Research in Organizational Behavior, 10(1), s. 123-167.

Avolio Bruce J., Zhu, Weıchun, Koh, Wıllıam ve Bhatia, Puja, (2004) "Transformational leadership and organizational commitment: mediating role of psychological empowerment and moderating role of structural distance", Journal of Organizational Behavior, 25(8), s. 951-68.

Aycan, Zeynep, (2006a) Paternalism, In Indigenous and cultural psychology (s. 445-466), Springer, Boston, MA.

Aycan, Zeynep, (2001), "Paternalizm: Liderlik Anlayışına İlişkin Üç Görgül Çalışma", Yönetim Araştırmaları Dergisi, $1(1)$, s. 11-33.

Aycan, Zeynep, (2006b) Paternalism: Towards conceptual refinement and operationalization, In K. S. Yang, K. K. Hwang, ve U. Kim (Eds.), Scientific advances in indigenous psychologies: Empirical, philosophical, and cultural contributions (s. 445-466). London: Sage Ltd.

Aycan, Zeynep, Kanungo, Rabindra N., Mendonca, Manuel, Yu, Kaicheng, Deller, Jürgen, Stahl, Günter, ve Kurshid, Aanwar, (2000) "Impact of culture on human resource management practices: A 10-country comparison", Applied Psychology, 49(1), s.192-221.

Aycan, Zeynep, Schyns, Birgit, Sun, Jian M., Felfe, Jörg, ve Saher, Noreen, (2013) "Convergence and divergence of paternalistic leadership: A cross-cultural investigation of prototypes", Journal of International Business Studies, 44(9), s.962-969.

Bayazıt, Mahmut, (2003) "Core self-evaluations scale adaptation study", Unpublished manuscript, İstanbul, Koç University, Department of Psychology.

Bedi, Akanksha, (2020) "A meta-analytic review of paternalistic leadership", Applied Psychology, 69(3), s. 960-1008.

Cheng, Bor, S., Chou, Li ,F. ve Farh, Jiing, L., (2000) "A Triad Model of Paternalistic Leadership: Constructs and measurement", Indigenous Psychological Research in Chinese Societies, 14, s.3-64.

Conger, Jay, A. ve Kanungo, Rabindra, N., (1988) "The Empowerment Process: Integrating Theory and Practice", Academy of Management Review, 13(3), s. 471-82.

Dedahanov, Alisher, T., Bozorov, Faridun, ve Sung, Sanghyun, (2019) "Paternalistic leadership and innovative behavior: Psychological empowerment as a mediator", Sustainability, 11(6), s.1770.

Demirer, Petek, (2012) "Is Paternalistic Leadership Empowering: A Contingency Framework”, Yüksek Lisans Tezi, Koç Üniversitesi Sosyal Bilimler Enstitüsü, İstanbul.

Dust, Scott, B., Resick, Christian, J., Margolis, Jaclyn, A., Mawritz, Mary, B., ve Greenbaum, Rebecca, L, (2018) "Ethical leadership and employee success: Examining the roles of psychological empowerment and emotional exhaustion", The Leadership Quarterly, 29(5), s. 570-583.

Erben, Gül Selin ve Güneşer, Ayşe Begüm, (2008) "The relationship between paternalistic leadership and organizational commitment: Investigating the role of climate regarding ethics", Journal of Business Ethics, 82(4), s. 955-968.

Ergeneli, Azize, Arı, Sağlam, G., ve Metin, Selin, (2007) "Psychological empowerment and its relationship to trust in immediate managers", Journal of Business Research, 60(1), s. 41-49.

Farh, Jiing, L., ve Cheng, Bor, S., (2000) A Cultural Analysis of Paternalistic Leadership in Chinese Organizations, in Management and Organizations in the Chinese Context, eds J. T. Li, A. S. Tsui, and E. Weldon (London, UK: Palgrave), s. 84-127.

Goodell, Grace E., Aronoff, Myron, J., Austin, Diane J., Cadeliña, Rowe, V., Emmerson, Donald, K., Hansen, Karen, T... ve Wiseman, John A., (1985) "Paternalism, Patronage, and Potlatch: The Dynamics of Giving and Being Given To [and Comments and Reply]", Current Anthropology, 26(2), s. 247-266.

Gouldner, Alvin, W., (1960) "The norm of reciprocity: A preliminary statement", American Sociological Review, s. 161-178.

Grošelj, Matej, Černe, Matej, Penger, Sandra ve Grah, Barbara, (2021) "Authentic and transformational leadership and innovative work behaviour: the moderating role of psychological empowerment", European Journal of Innovation Management, 24(3), s.677-706.

Hechanova, Ma R. M., Alampay, Ramon B. A., ve Franco, Edna P., (2006) "Psychological empowerment, job satisfaction and performance among Filipino service workers", Asian Journal of Social Psychology, 9(1), s. 72-78.

Henry, Paul,C., (2005) "Social Class, Market Situation, and Consumers' Metaphors of (Dis)empowerment", Journal of Consumer Research, 31(4), s.766-778.

Hiller, Nathan, J., Sin, Hock, P., Ponnapalli, Ajay, R., ve Ozgen, Sibel, (2019) "Benevolence and authority as WEIRDly unfamiliar: A multi-language meta-analysis of paternalistic leadership behaviors from 152 studies", The Leadership Quarterly, 30(1), s.165-184.

$\mathrm{Hu}$, Jia, Wang, Zhen, Liden, Robert, C. ve Sun, Jianmin, (2012) "The influence of leader core self-evaluation on follower reports of transformational leadership", The Leadership Quarterly, 23(5), s.860-868. 
Hu, Yixin, Zhu, Liping, Zhou, Mengmeng, Li, Jie, Maguire, Phil, Sun, Haichao ve Wang, Dawei, (2018) "Exploring the influence of ethical leadership on voice behavior: how leader-member exchange, psychological safety and psychological empowerment influence employees' willingness to speak out”, Frontiers in Psychology, 9, s. 1718.

Joo, Baek, K., ve Lim, Taejo, (2013) "Transformational leadership and career satisfaction: The mediating role of psychological empowerment”, Journal of Leadership \& Organizational Studies, 20(3), s.316-326.

Judge, Timothy, A. ve Bono, Joyce, E., (2001) "Relationship of core self-evaluations traits-self-esteem, generalized selfefficacy, locus of control, and emotional stability-with job satisfaction and job performance: a meta-analysis”, Journal of Applied Psychology, 86(1), s. 80-92.

Judge, Timothy, A., Erez, Amır, Bono Joyce, E., Thoresen, Carl, J., (2003) “The core self-evaluations scale: development of a measure", Pers Psychol, 56 (2), s.303-331.

Judge, Timothy, A., Locke, Edwin, A., Durham, Cathy, C. ve Kluger, Avraham, N., (1998) "Dispositional effects on job and life satisfaction: the role of core evaluations", J. Appl. Psychol. 83(1), s.17-34.

Khuwaja, Uzair, Ahmed, Kaleem, Abid, Ghulam ve Adeel, Ahmad, (2020) "Leadership and employee attitudes: The mediating role of perception of organizational politics", Cogent Business \& Management, 7(1), s.1-21.

Kisbu, Yasemin, (2006) "Influences Of Regulatory Focus, Core Self Evaluations And Age On Biases In Perception and Choıce”, Yüksek Lisans Tezi, Koç Üniversitesi Sosyal Bilimler Enstitüsü, İstanbul.

Krishnan, Venkat, R., (2012) "Transformational leadership and personal outcomes: empowerment as mediator", Leadership \& Organization Development Journal, 33 (6), s.550-563.

Lau, Wai, K., Pham, Loan, N., ve Nguyen, Lam, D., (2019) "Remapping the construct of paternalistic leadership", Leadership \& Organization Development Journal, 40(7), s.764-776.

Lee, Kyootai, Scandura, Terri, A. ve Sharif, Monica, M., (2014) "Cultures have consequences: A configural approach to leadership across two cultures", The Leadership Quarterly, 25(4), s.692-710.

Li, Chenwei, Wu, Keke, Johnson, Diane E. ve Wu, Min, (2012) "Moral leadership and psychological empowerment in China", Journal of Managerial Psychology, 27(1), s. 90-108.

Li, Xiufeng ve Lin, Congcong, (2020), "The influence of high-commitment work system on work well-eing: the mediating role of psychological empowerment and the moderating role of leader trust", Personnel Review, 50 (4), s. 11281147.

Lin, Cai, H. V. ve Sun, Jian, M. J., (2018) “Chinese employees' leadership preferences and the relationship with power distance orientation and core self-evaluation", Frontiers of Business Research in China, 12(1), s.1-22.

Lin, Chun, P., Lin, Mei, Z. ve Li, Yi, B., (2015) “An empirical study on the effect of paternalistic leadership on employees' voice behaviors-the intermediary role of psychological empowerment", Journal of Interdisciplinary Mathematics, 18(6), s. 789-810.

Mansur, Juliana, Sobral, Filipe ve Goldszmidt, Rafael, (2017) “Shades of paternalistic leadership across cultures”, Journal of World Business, 52(5), s.702-713.

Marta, Iman, A., Supartha, I Wayan Gede, Dewi, I, G. A. M ve Wibawa, I Made Artha, (2021) "Job Enrichment, Empowerment, and Organizational Commitment: The Mediating Role of Work Motivation and Job Satisfaction", The Journal of Asian Finance, Economics, and Business, 8(1), s.1031-1040.

Maynard, Travis, M. Gilson, Lucy, L. ve Mathieu, John, E., (2012) "Empowerment—fad or fab? A multilevel review of the past two decades of research", Journal of Management, 38(4), s.1231-1281.

Meyerson, Shauna, L. ve Kline, Theresa, J.B., (2008) "Psychological and environmental empowerment: antecedents and consequences", Leadership \& Organization Development Journal, 29(5), s. 444-460.

Mubarak, Fozia, ve Noor, Ayesha, (2018) "Effect of authentic leadership on employee creativity in project-based organizations with the mediating roles of work engagement and psychological empowerment", Cogent Business \& Management, 5(1), s.1-14.

Mussolino, Donata ve Calabrò, Andrea, (2014) "Paternalistic leadership in family firms: Types and implications for intergenerational succession", Journal of Family Business Strategy, 5(2), s. 197-210.

Newman, Alexander, Schwarz, Gary, Cooper, Brian ve Sendjaya, Sen, (2017) "How servant leadership influences organizational citizenship behavior: The roles of LMX, empowerment, and proactive personality", Journal of Business Ethics, 145(1), s.49-62.

Nübold, Annika, Muck, Peter, M. ve Maier, Güntar, W., (2013) “A new substitute for leadership? Followers' state core self-evaluations", The Leadership Quarterly, 24(1), s.29-44.

Ölçer, Ferit ve Florescu, Margareta,S., (2015) "Mediating effect of job satisfaction in the relationship between psychological empowerment and job performance", Theoretical and Applied Economics, 22(3), s.111-136.

Paşa, Selda, F., Kabasakal, Hayat veBodur,Muzaffer, (2001) "Society, organizations, and leadership in Turkey", Applied Psychology: An International Review, 50 (4), s.559-589.

Pellegrini, Ekin, K. ve Scandura, Terri, A., (2006) "Leader-member exchange (LMX), paternalism, and delegation in the Turkish business culture: An empirical investigation”, Journal of International Business Studies, 37(2), s. 264279.

Pellegrini, Ekin, K., ve Scandura, Terri, A., (2008) "Paternalistic leadership: A review and agenda for future research", Journal of Management, 34(3), s. 566-593. 
Pieterse, Anne, N., Van Knippenberg, Daan, Schippers, Michaela ve Stam, Daan, (2010) “Transformational and transactional leadership and innovative behavior: The moderating role of psychological empowerment", Journal of Organizational Behavior, 31(4), s. 609-623.

Pradhan, Rabindra, K., Panda, Madhusmita ve Jena, Lalatendu, K., (2017) "Transformational leadership and psychological empowerment: The mediating effect of organizational culture in Indian retail industry", Journal of Enterprise Information Management, 30(1), s.82-95.

Sağlam, Arı, G., (2014) "Örgütlerde Fiziksel Semboller ve Psikolojik Güçlendirme İlişkisi Üzerine Kavramsal Bir Çalıșma". H.Ü. İktisadi ve İdari Bilimler Fakültesi Dergisi, 32(2), s. 1-25.

Silin, Robert, H., (1976) Leadership and Values: The Organization of Large-Scale Taiwanese Enterprises. Harvard Univ Asia Center.

Spreitzer, Gretchen, M., (1995) "Psychological empowerment in the workplace: Dimensions, measurement, and validation", Academy of Management Journal, 38(5), s.1442-1465.

Spreitzer, Gretchen, M., (1996) "Social structural characteristics of psychological empowerment”, Academy of Management Journal, 39(2), s.483-504.

Sürgevil, Olca, Tolay, Ebru, Topoyan, Mert, (2013) "Yapısal Güçlendirme ve Psikolojik Güçlendirme Ölçeklerinin Geçerlilik ve Güvenilirlik Analizleri”, Journal of Yasar University, 8(31), s. 5371-5391.

Taştan, Bal S., (2013) "The relationship between psychological empowerment and psychological well being: the role of self-efficacy perception and social support”. Öneri Dergisi, 10(40), s.139-154.

Thomas, Kenneth, W. ve Velthouse, Betty, A., (1990) “Cognitive Elements of Empowerment: An "Interpretive" Model of Intrinsic Task Motivation”, The Academy of Management Review, 15(4), s. 666-681.

Tuuli, Martin, M., ve Rowlinson, Steve, (2009) "Performance consequences of psychological empowerment", Journal of Construction Engineering and Management, 135(12), s.1334-1347.

Usman, Muhammad, Liu, Yuxin, Li, Haihong, Zhang, Jianwei, Ghani, Usman, ve Gul, Habib, (2020) "Enabling the engine of workplace thriving through servant leadership: The moderating role of core self-evaluations", Journal of Management \& Organization, s. 1-19.

Wagstaff, Maria, F., Collela, Adrienne, Triana, Maria, D.C., Smith, Alexis, N. ve Watkins, Marla, B., (2015) "Subordinates' perceptions of supervisor paternalism: A scale development." . Journal of Managerial Psychology, 30(6), s. 659-674.

Wang, An, C. ve Cheng, Bor, S., (2010) "When does benevolent leadership lead to creativity? The moderating role of creative role identity and job autonomy", Journal of Organizational Behavior, 31(1), s.106-121.

Wei, Feng, Yuan, Xin ve Di, Yang, (2010) "Effects of transactional leadership, psychological empowerment and empowerment climate on creative performance of subordinates: A cross-level study", Frontiers of Literary Studies in China, 4(1), s. 29-46.

Wu, Melien, Zhuang, Wen, L., ve Hung, Chao, C. (2014) “The effects of mentoring functions on repatriate adjustmentModerating role of core self-evaluations", International Journal of Intercultural Relations, 43, s.177-188.

Yazıcıŏ̆lu, Yahşi ve Erdoğan, Samiye, (2004) SPSS uygulamalı bilimsel araştırma yöntemleri, Detay Yayıncılık, Ankara.

Zhang, Jing, Song, Lynda, J., Wang, Yue ve Liu, Guangjian, (2018) "How authentic leadership influences employee proactivity: the sequential mediating effects of psychological empowerment and core self-evaluations and the moderating role of employee political skill". Frontiers of Business Research in China, 12(1), s. 1-21.

Zhang, Yan, Huai, Ming, Y. ve Xie, Yun, H., (2015) "Paternalistic leadership and employee voice in China: A dual process model", The Leadership Quarterly, 26(1),s. 25-36.

Zhi-Hua, D. E. N. G., (2016) “Comparative study of servant leadership and paternalistic leadership on employee's performance", DEStech Transactions on Engineering and Technology Research, (ssme-ist).

Zimmerman, Marc, A., (1995) "Psychological empowerment: Issues and illustrations", American Journal of Community Psychology, 23(5), s. 581-599. 